\title{
COMPORTAMENTO E INFLUÊNCIA DO ALBEDO E TEMPERATURA DE SUPERFÍCIE NO BALANÇO DE RADIAÇÃO EM ÁREAS DE CERRADO
}

\author{
Marcos Esdras Leite \\ Universidade Estadual de Montes Claros - UNIMONTES \\ Professor Dr. do Departamento de Geociências \\ marcosesdrasleite@gmail.com \\ Lucas Augusto Pereira da Silva \\ Universidade Estadual de Montes Claros - UNIMONTES \\ Mestrando do Programa de Pós-Graduação em Geografia - PPGEO \\ lucasaugustounimontes@gmail.com \\ Gabriel Alves Veloso \\ Universidade Federal do Pará - UFPA \\ Professor Dr. da Faculdade de Geografia \\ gabrielveloso.geo@gmail.com \\ Raul de Magalhães Filho \\ Universidade Estadual de Montes Claros - UNIMONTES \\ Mestrando do Programa de Pós-Graduação em Geografia - PPGEO \\ rauldemagalhaesf@gmail.com
}

\begin{abstract}
RESUMO
O presente trabalho tem por objetivo compreender o comportamento e a influência do albedo e da temperatura de superfície no balanço de radiação, considerando diferentes usos e coberturas da terra em áreas de Cerrado no Norte de Minas Gerais. Para realização da pesquisa, foram utilizados produtos orbitais do satélite Landsat8 (OLI/TIRS), para órbita/ponto 219/070. Para a mensuração dos componentes do balanço de radiação, utilizouse o algoritmo SEBAL adaptado para o satélite Landsat8. No que toca aos resultados, observou-se influência do albedo e da temperatura de superfície no balanço de radiação, sobretudo considerando a sazonalidade climática imposta na área de estudo. Do ponto de vista operacional, o presente trabalho foi realizado com dados de fácil acesso e manipulação, sendo atrativos para novos estudos no âmbito da ciência geográfica. Quanto à validação científica dos dados, é importante destacar que eles se mostraram consistentes, com pequenas diferenças (somente com valores destoantes para dois produtos) ao comparar com os dados de referência em superfície, neste caso, os dados do INMET.
\end{abstract}

Palavras-Chave: Albedo. Temperatura de superfície. Balanço de radiação e Sensoriamento Remoto.

\section{BEHAVIOR AND INFLUENCE OF THE SURFACE AND SURFACE TEMPERATURE IN THE RADIATION BALANCE IN CLOSED AREAS}

\begin{abstract}
The present work aims to understand the behavior and influence of albedo and surface temperature in the radiation balance considering different uses and land cover in Cerrado areas in the North of Minas Gerais. To perform the research, orbital producTemperatura de superfície of the Landsat 8 satellite (OLI / TIRS) were used for orbit and point 219/070. For the measurement of the componenTemperatura de superfície of the radiation balance, the SEBAL algorithm was adapted to the Landsat8 satellite. Regarding the resulTemperatura de superfície, the influence of albedo and surface temperature on the radiation balance was observed, especially considering the climatic seasonality imposed in the study area. From the operational point of view, the present work was accomplished in a short time with data of easy access and manipulation, being attractive for new studies in the scope of geographic science. Regarding the scientific validation of the data, it is important to highlight that the data were consistent, with small differences when compared with the reference surface data, in this case, the INMET data.
\end{abstract}

Keywords: Albedo. Surface temperature. Radiation balance and Remote Sensing.

Caminhos de Geografia Uberlândia $\quad$ v. 21, n. $73 \quad$ Mar/2020 $\quad$ p. 131-147 Página 131




\section{INTRODUÇÃO}

As alterações dos usos e das coberturas da terra em diversas escalas vêm causando influências significativas em fatores abióticos, sobretudo os relacionados às trocas de energia entre a superfície e a atmosfera. Essas alterações podem acarretar em novas dinâmicas de cunho negativo nas variáveis abióticas, os impactos no uso da terra podem alterar a dinâmica regional e global atmosférica, alterando fatores como a temperatura e a umidade do ar e a precipitação, bem como a qualidade dos recursos hídricos (PEREIRA, 2013; NÓBREGA, 2014; PAULA et al., 2016; MONTEIRO, 2016).

No Cerrado brasileiro, as alterações no uso e na cobertura da terra têm se intensificado diante do devir histórico, e do ponto de vista da dinâmica superfície-atmosfera são evidenciadas inferências nessa interação, sobretudo na variabilidade da temperatura de superfície, do ar, da emissão de carbono, de fluxos de energia, da evapotranspiração e do balanço hídrico (TASCH, 2006; SANTOS, 2010; URQUIAGA, 2010;CARVALHO et al., 2011; ATAÍDE, 2012; GIOANOTTI et al., 2013; REIS et al., 2014; MARTINS et al., 2015; FAUSTO et al., 2016; ANGELINI et al., 2017; JESUS et al, 2017). Com isso, a comunidade científica vem desenvolvendo métodos que evidenciam como os efeitos da alteração do uso e da cobertura da terra podem impactar nas trocas energéticas na baixa atmosfera. Dentre estes métodos utilizados para efetuar essas estimativas, podem ser citados aparelhos convencionais como o saldoradiômetro para medição do saldo de radiação, as equações teórico-metodológicas, como razão de Bowen (BOWEN, 1926), os vórtices turbulentos, o método Priestley-Taylor (FIETZ e FISCH, 2008; HELDWEIN et al., 2012; PEREIRA et al., 2013; JUNG et al., 2016; JÚNIOR, 2019). No entanto, essas estimativas são limitadas a áreas pequenas e homogêneas, portanto, com pouca representatividade espacial (SILVA et al., 2005; GUSMÃO et al., 2012).

Esses dados com pouca representação espacial são utilizados como referências terrestres em metodologias que possam abranger pequenas escalas, como aquelas que utilizam as técnicas do sensoriamento remoto, assumindo, assim, um papel ímpar nas análises desses parâmetros biofísicos, visto que aquele abarca diversas faixas do espectro eletromagnético, bem como o termal infravermelho próximo, médio e visível que são substanciais nas análises de dinâmicas entre a superfície e a baixa atmosfera, sobretudo absorção, reflexão e emissão (BEZERRA et al., 2008; JENSEN, 2011).

Das variáveis climáticas e meteorológicas que podem ser estimadas por meio do sensoriamento remoto é imprescindível mencionar os balanços de ondas curtas e ondas longas, que representam em seu somatório o balanço/saldo de radiação à superfície (VAREJÃO-SILVA, 2006; MACHADO et al., 2014; SILVA et al., 2016; PEREIRA e JUNIOR, 2017).

Nesse sentido, é preciso compreender quais variáveis influenciam o balanço de radiação, dentre essas a reflexão de ondas curtas e o aquecimento da superfície terrestre podem ser indicadores de influência no balanço de radiação, sobretudo em função do uso e da cobertura da terra, haja vista que estudos apontam a sensibilidade de tais variáveis quanto às alterações no uso da terra (BEZERRA et al., 2014; SANTOS et al., 2014; MACEDO et al., 2015; SILVA et al., 2015; ALVES et al., 2017; CONCEIÇÃO, 2018; DUBASTIANI et al., 2018).

Para tanto, como uma das metodologias de destaque para a estimativa desses parâmetros biofísicos com dados satelitários, atribuiu-se o uso do algoritmo SEBAL (Surface Energy Balance Algorithm Land) para a obtenção dos componentes do balanço de radiação. Este algoritmo é amplamente utilizado e testado em pesquisas no Cerrado brasileiro em análises biofísicas com a utilização de vários sensores, entre eles o Enhanced Thematic Mapper Plus - ETM+ (Landsat 7), o Thematic Mapper - TM (Landsat 5), os sensores Moderate Resolution Imaging Spectraradiometer - MODIS (plataforma Terra e Aqua), e, mais recentemente, os sensores Operation Land Imager - OLI e Thermal Infrared Sensor - TIRS (Landsat 8). (GOMES et al., 2009; GIONGO, 2010; FAUSTO et al., 2016; MARTINS e ROSA, 2019).

No caso, a aplicação dessa metodologia em imagens de resolução espacial médio-alta, como as do sensor OLI/TIRS do satélite Landsat8, pode trazer a compreensão desses parâmetros numa escala regional ou até mesmo local, podendo auxiliar na gestão e no planejamento ambiental no intuito de torná-las mais ambientalmente sustentáveis.

Assim, este trabalho tem por objetivo analisar o comportamento e a influência do albedo e da temperatura de superfície no balanço de radiação para diferentes usos e coberturas da terra em áreas de Cerrado no Norte de Minas Gerais. Esta pesquisa se justifica pelo fato de a área de estudo não haver análises que envolva a dinâmica Terra-Atmosfera em função do uso e da cobertura da terra, sendo uma área de extrema importância por estar em proximidade com a maior Área de Proteção Ambiental de Minas Gerais (APA do Rio Pandeiros).

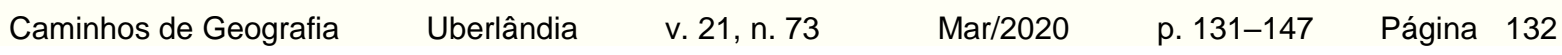




\section{MATERIAIS E MÉTODOS}

\section{Caracterização da área de estudo}

O estudo foi desenvolvido em uma área de Cerrado no Norte do estado de Minas Gerais, estando parte inserida na Área de Preservação Ambiental (APA) do Rio Pandeiros (Figura 1):

Figura 1 - Localização.

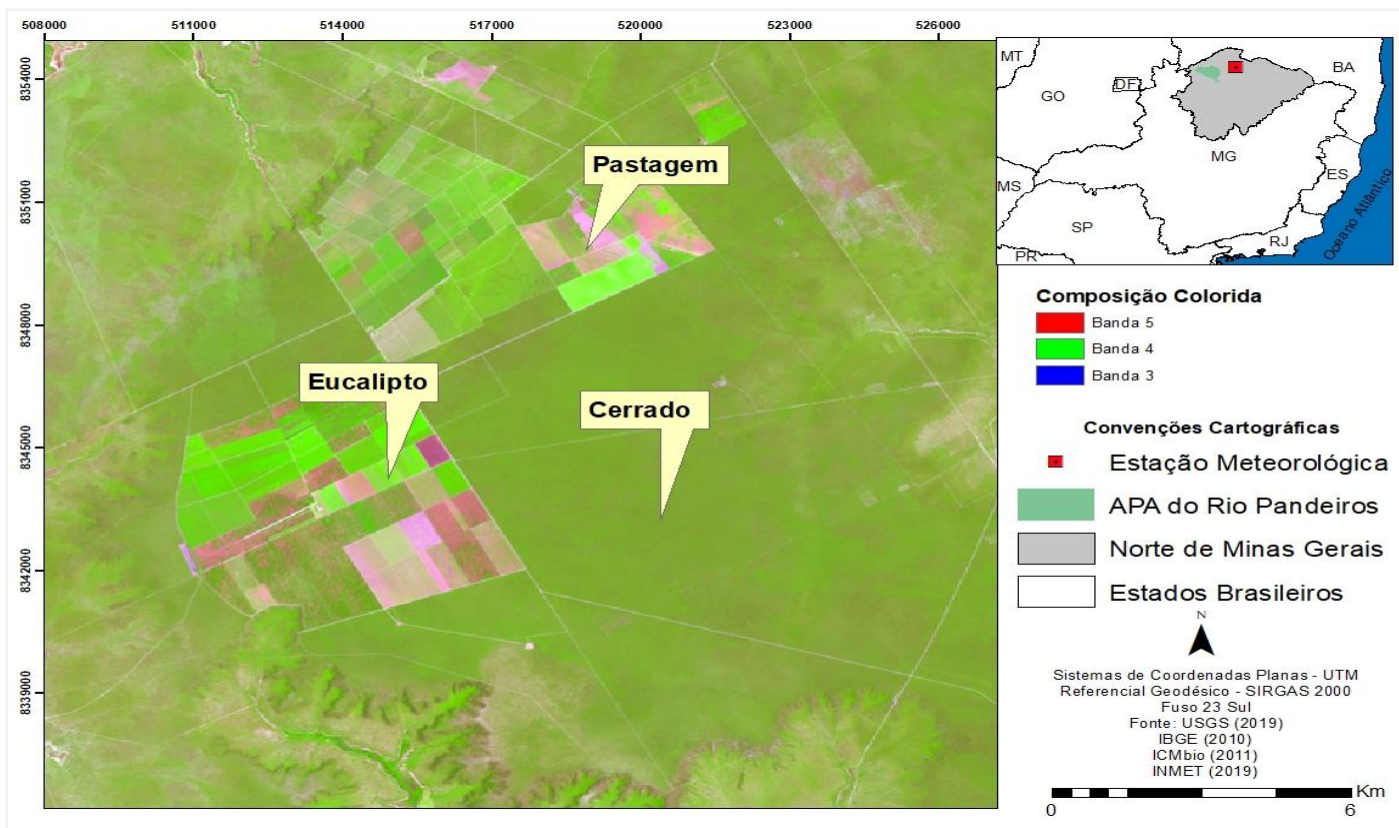

Fonte - Os autores, 2019.

O clima da área de estudo é marcado pelo Tropical subúmido-úmido com transição para subúmidoseco, com concentração das chuvas entre março e outubro (ALMEIDA, 2016). A média anual dos índices pluviométricos estão entre 900 e 1250 mm (ANTUNES, 1994; ALMEIDA, 2016).

No contexto geológico, a área analisada está sobre a formação Serra de Santa Helena. A APA possui as seguintes unidades geológicas: grupo areado, complexo Januária, grupo Urucuia, cobertura superficial indiferenciada, formação Serra de Santa Helena, formação sete lagoas e depósito aluvial, tendo distribuição espacial $0,29 \%, 4,25 \%, 72,84 \%, 15,16 \%, 0,47 \%, 0,62 \%) 6,37 \%$, respectivamente (SILVA, 2018).

A média altimétrica do recorte é de 810 metros, isso levando em consideração a variação topográfica da APA, sendo 449 a 846 metros (SRTM, 2002). A declividade do recorte varia de 0 a 2,68\%, enquanto a declividade da APA possui variação das classes de 0 a 2,68\%, 2,69 a 5,81\%, 5,82 a 11,84\%, 11,85 a $22,35 \%$ e 22,36 a 56,99\%, nesse sentido, o relevo tem variação de plano a montanhoso.

Os solos da APA estão distribuídos em: cambissolo háplico, gleissolo melânico, latossolo vermelhoamarelo, neossolo flúvico, neossolo litólico e neossolo quartzaranênico, sendo que as áreas amostradas estão dispostas em latossolo vermelho-amarelo (UFV, 2010).

No contexto de cobertura da terra, a área de estudo possui variações fitofisionômicas de Cerradão, Cerrado stricto sensu, Floresta Estacional Decidual e Veredas. As paisagens antrópicas são marcadas por sistemas agropastoris, reflorestamento, áreas destinadas a cultivos agrícolas, dentre outros. (ALMEIDA, 2016; LEITE et al., 2018).

\section{PROCEDIMENTOS TÉCNICO-OPERACIONAIS}

Para realização deste trabalho, foram utilizados produtos orbitais do satélite Landsat8 (OLI/TIRS) para a órbita 219 e ponto 070 , referindo-se às seguintes datas: 10/01/2015, 22/08/2015, 01/03/2016, 08/08/2016, 27/08/2017, 29/07/2018, 20/12/2018, 20/01/2019. A escolha dessas datas possibilitou 
analisar a dinâmica dos componentes biofísicos na área de estudos em relação ao tempo (período de análise), bem como ao espaço (alterações no uso e na ocupação do solo).

$\mathrm{Na}$ Tabela 1, estão dispostas as características das bandas do Landsat8, que foram utilizadas neste estudo:

Tabela 1 - Características das bandas utilizadas.

\begin{tabular}{|c|c|c|c|c|}
\hline Sensores & Bandas & $\begin{array}{l}\text { Faixas } \\
\text { Espectrais }\end{array}$ & $\begin{array}{l}\text { Comprimento de onda } \\
\text { (micrometros) }\end{array}$ & $\begin{array}{c}\text { Resolução } \\
\text { Espacial } \\
\text { (metros) }\end{array}$ \\
\hline$\overline{\mathrm{OLI}}$ & 2 & Visível Azul & $0.45-0.51$ & 30 \\
\hline \multirow[t]{6}{*}{ TIRS } & 3 & Visível Verde & $0.53-0.59$ & 30 \\
\hline & 4 & Visível Vermelho & $0.64-0.67$ & 30 \\
\hline & 5 & Infravermelho Próximo & $0.85-0.88$ & 30 \\
\hline & 6 & Infravermelho Médio/SWIR & $1.57-1.65$ & 30 \\
\hline & 7 & Infravermelho Médio/SWIR & $2.11-2.19$ & 30 \\
\hline & 10 & Infravermelho Termal (TIRS) & $10.60-11.19$ & 100 \\
\hline
\end{tabular}

Fonte - USGS, 2013. Org.: Os autores, 2019.

De posse das imagens, foram realizadas as composições coloridas (RGB), utilizando as 7 bandas com intuito da entrada no algoritmo SEBAL. A composição foi realizada no software Erdas Imagine 2014, por meio da ferramenta layerstack. Em seguida, foi realizada a foto-leitura nas imagens, a fim de identificar os usos e as coberturas da terra a serem amostrados.

Posteriormente, foi realizada a modelagem dos componentes do balanço de radiação. Para esta etapa, foi necessário o uso do ModelMaker, disponível no Erdas, sendo um modelador matemático que permite a entrada das expressões lógicas do SEBAL. Nesse sentido, seguem as etapas de cálculo do algoritmo:

\section{Etapa 1: Conversão radiométrica e da reflectância}

Esta etapa consiste na conversão dos níveis digitais (ND) em reflectância e em correção atmosférica, a partir da seguinte expressão (ALVES et al., 2017):

$$
\rho \lambda, b=\frac{H \rho Q C A L+A \rho}{\cos (\theta S E)}
$$

Onde $\rho \lambda, b$ é a Refletância monocromática representando todas as bandas, $H \rho$ redimensionamento multiplicativo específico de cada banda (valor constante - 0,1 ), A é ao fator aditivo (valor constante $2 \mathrm{E}-5), Q C A L$ valor pixel a pixel de cada banda (ND) e $\theta S E$ ângulo azimutal, que é calculado da seguinte maneira:

$$
\theta \mathrm{SE}=90-\theta \mathrm{S} Z
$$

Sendo $\theta S Z$ o ângulo de elevação do sol, que está disponível nos metadados.

\section{Etapa 2: Obtenção do albedo de superfície}

O albedo de superfície, ainda sem correção atmosférica, foi obtido a partir das reflectâncias das bandas de 2 a 7 do satélite Landsat8, sendo obtido por meio de combinação linear das refletâncias espectrais $\rho \lambda, b$, com pesos $\varpi \lambda, b$ estabelecido para cada banda, sendo a expressão:

$$
\text { atoa }=\left(\varpi 2^{*} \rho \lambda, 2\right)+\left(\varpi 3^{*} \rho \lambda, 3\right)+\left(\varpi 4^{*} \rho \lambda, 4\right)+\left(\varpi 5^{*} \rho \lambda, 5\right)+\left(\varpi 6^{*} \rho \lambda, 6\right)+\left(\varpi 7^{*} \rho \lambda, 7\right)
$$

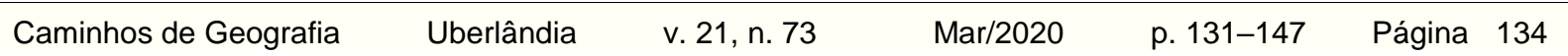


Os pesos para cada banda foram obtidos, conforme Ruhoff et al., (2015), Alves et al., (2017) e Silva et al., (2016). Esses pesos são extraídos em função da razão da irradiância no topo da atmosfera.

A obtenção do albedo de superfície se deu por meio da equação 8 recomendada por Allen et. al. (2002).

$$
\alpha=\frac{\alpha_{\text {toa }}-\alpha_{p}}{\tau_{s w}{ }^{2}}
$$

Sendo que atoa é o albedo planetário (sem correções atmosféricas) e ap é reflectância da atmosfera, variando de 0,025 a 0,04. E tSw é a transmissividade da atmosfera no tocante às ondas curtas refletidas, que nas condições de transparência calcula-se utilizando a equação 9 , de acordo com Allen et. al. (2002).

$$
\tau_{s w}=0,75+2 \times 10^{-5} z
$$

Em que $z$ foi obtido pela altitude da estação meteorológica de referência deste estudo.

\section{Etapa 3: obtenção da temperatura de superfície}

Para obter a temperatura de superfície, foi necessário o uso da banda termal do sensor TIRS (Thermallnfrared Sensor), sendo a banda 10; empregando os fatores de reescalonamento da radiância fornecidos nos metadados:

$$
\mathrm{L} \lambda=\mathrm{MLQcal}+\mathrm{AL}
$$

Onde: $L \lambda$ é a radiância monocromática, $M L$ é o fator de reescalonamento multiplicativo específico (3,342x10-4), AL é o fator de reescalonamento aditivo específico $(0,1)$, e Qcal é o valor pixel a pixel da imagem de satélite. Na equação 11, tem-se a obtenção da temperatura:

$$
\mathrm{TS}=\frac{K 2}{\left(I n \frac{k 1}{\mathrm{~L} \lambda}+1\right)}(11)
$$

\section{Etapa 4: Saldo de radiação}

O saldo de radiação foi obtido pela seguinte expressão:

$$
R n=(1-\alpha) \cdot R s+R o l, a t m-\text { Rol,emi- }(1-\varepsilon 0) \cdot \text { Rol,atm }
$$

Onde: $\alpha$ é o albedo de superfície; Rs é a radiação de onda curta incidente; Rol,atm é a radiação de onda longa incidente; Rol,emi é a radiação de onda longa emitida, e $\varepsilon 0$ é a emissividade da superfície $(4-100 \mu \mathrm{m})$.

Após o processamento e a obtenção dos dados do algoritmo SEBAL, buscou-se a validação, sobretudo a partir dos produtos termais da etapa 3. Para tanto, foi necessária a obtenção de dados meteorológicos na estação de Mocambinho - MG. Os dados para validação foram as médias de temperatura do ar no horário da passagem do sensor.

A fim de compreender a influência do albedo e da temperatura no saldo de radiação, foi necessário extrair amostras de usos da terra. Para este fim, selecionou-se 3 classes de usos da terra, sendo Cerrado stricto senso, eucalipto e pastagem. Foram extraídos 4259 pontos para áreas de Cerrado, 534

$\begin{array}{lllll}\text { Caminhos de Geografia } & \text { Uberlândia } & \text { v. 21, n. } 73 & \text { Mar/2020 } & \text { p. 131-147 Página } 135\end{array}$


para eucalipto e 400 para pastagens. O elevado número para Cerrado se justifica devido às vastas áreas homogêneas encontradas na chapada.

Quanto à representação dos dados, do ponto de vista da espacialização, foram expostas as cartas de albedo, a temperatura de superfície e o saldo de radiação em 3 mapas. Quanto à discussão, para as áreas amostradas (Cerrado, eucalipto e pastagem), foram extraídos valores mínimos, médios, máximos e desvio padrão para cada período, e, para sintetizar a discussão, fez-se necessário extrair os valores médios para mínima média, máxima e desvio padrão, separando-os em seco e úmido.

\section{RESULTADOS E DISCUSSÃO}

\section{Espacialização do Albedo, Temperatura de superfície e Saldo de Radiação}

A aplicação das técnicas de sensoriamento remoto na estimativa de dados biofísicos como o Albedo de superfície e o saldo de radiação é de grande relevância, dada a grande variabilidade destes fenômenos no espaço, principalmente em grandes áreas, condicionado a uma série de fatores e restrições ambientais (variabilidade temporal), tais como: fatores climáticos, radiação solar, temperatura, umidade relativa do ar e vento, bem como fatores relacionados à vegetação, como estágio de desenvolvimento foliar, altura e profundidade do sistema radicular, de manejo e do solo, além da declividade do terreno. Dessa forma, devido às diferenças dos elementos que compõem a paisagem, a determinação do albedo de superfície e do Saldo de radiação, levando-se em consideração a sua variabilidade espacial e temporal, é de significativa importância.

$\mathrm{Na}$ Tabela 2, estão apresentados os valores médios para cada imagem e as estatísticas (mínimo, máximo, médio e desvio padrão) gerais dos produtos para período seco e úmido.

Tabela 2 - Estatísticas dos produtos

\begin{tabular}{|c|c|c|c|c|c|c|c|c|c|}
\hline & Cerrado & & & & Eucalipto & & Pastagem & & \\
\hline $\begin{array}{l}\text { Período } \\
\text { seco }\end{array}$ & Albedo & $\begin{array}{l}\text { Temperatur } \\
\text { a de } \\
\text { superfície } \\
\left({ }^{\circ} \mathrm{C}\right)\end{array}$ & $\begin{array}{c}\text { RnWm- } \\
2\end{array}$ & Albedo & $\begin{array}{c}\text { Temperatur } \\
\text { a de } \\
\text { superfície } \\
\left({ }^{\circ} \mathrm{C}\right)\end{array}$ & $\begin{array}{c}R n \\
W m^{-2}\end{array}$ & Albedo & $\begin{array}{l}\text { Temperatur } \\
\text { a de } \\
\text { superfície } \\
\left({ }^{\circ} \mathrm{C}\right)\end{array}$ & $\begin{array}{c}\mathrm{Rn} \text { Wm- } \\
2\end{array}$ \\
\hline $28 / 08 / 2015$ & 0,12 & 28,82 & 600,66 & 0,12 & 28,95 & 600,32 & 0,29 & 33,08 & 440,12 \\
\hline 08/08/2016 & 0,11 & 28,09 & 584,48 & 0,15 & 29,71 & 537,66 & 0,22 & 34,79 & 457,36 \\
\hline $27 / 08 / 2017$ & 0,13 & 29,04 & 599,3 & 0,16 & 33,31 & 542,18 & 0,22 & 31,58 & 510,8 \\
\hline $29 / 07 / 2018$ & 0,11 & 24,04 & 568,54 & 0,11 & 29,96 & 532,27 & 0,34 & 26,72 & 383,69 \\
\hline Mínimo & 0,11 & 24,04 & 568,54 & 0,11 & 28,95 & 532,27 & 0,22 & 26,72 & 383,69 \\
\hline Médio & 0,12 & 27,50 & 588,25 & 0,135 & 30,4825 & 553,11 & 0,27 & 31,54 & 447,99 \\
\hline Máximo & 0,13 & 29,04 & 600,66 & 0,16 & 33,31 & 600,32 & 0,34 & 34,79 & 510,8 \\
\hline Desv. & 0,01 & 1,73 & 11,74 & 0,02 & 1,41 & 23,61 & 0,05 & 2,41 & 36,09 \\
\hline $\begin{array}{c}\text { Período } \\
\text { úmido }\end{array}$ & Albedo & $\begin{array}{c}\text { Temperatur } \\
\text { a de } \\
\text { superfície } \\
\left({ }^{\circ} \mathrm{C}\right)\end{array}$ & $\begin{array}{c}\mathbf{R n} \\
W m-^{2}\end{array}$ & Albedo & $\begin{array}{c}\text { Temperatur } \\
\text { a de } \\
\text { superfície } \\
\left({ }^{\circ} \mathrm{C}\right)\end{array}$ & $\begin{array}{c}R n \\
W m^{-2}\end{array}$ & Albedo & $\begin{array}{c}\text { Temperatur } \\
\text { a de } \\
\text { superfície } \\
\left({ }^{\circ} \mathrm{C}\right)\end{array}$ & $\begin{array}{c}\text { Rn Wm- } \\
2\end{array}$ \\
\hline $10 / 01 / 2015$ & 0,14 & 24,12 & 676,51 & 0,14 & 25,43 & 668,03 & 0,2 & 25,4 & 618,69 \\
\hline 01/03/2016 & 0,13 & 29,32 & 656,11 & 0,12 & 30,25 & 655,57 & 0,19 & 32,91 & 574,39 \\
\hline $20 / 12 / 2018$ & 0,12 & 28,96 & 681,37 & 0,15 & 35,78 & 618,38 & 0,2 & 29,87 & 606,83 \\
\hline $21 / 01 / 2019$ & 0,12 & 29,19 & 673,36 & 0,15 & 35,88 & 609,84 & 0,2 & 29,98 & 594,98 \\
\hline Mínimo & 0,12 & 24,12 & 656,11 & 0,12 & 25,43 & 609,84 & 0,19 & 25,4 & 574,39 \\
\hline Médio & 0,13 & 27,90 & 671,84 & 0,14 & 31,835 & 637,96 & 0,20 & 29,54 & 598,72 \\
\hline Máximo & 0,14 & 29,32 & 681,37 & 0,15 & 35,88 & 668,03 & 0,2 & 32,91 & 618,69 \\
\hline Desv. & 0,01 & 1,89 & 7,86 & 0,01 & 4,00 & 23,85 & 0,00 & 2,07 & 14,04 \\
\hline
\end{tabular}

Fonte - Os autores, 2019.

Salienta-se que esses valores serão sintetizados em seco e em úmido para que se possa compreender a dinâmica da sazonalidade climática de maneira mais generalizada. Os dados de albedo especializados para a área de estudo estão dispostos na Figura 2: 
Figura 2 - Espacialização do Albedo.
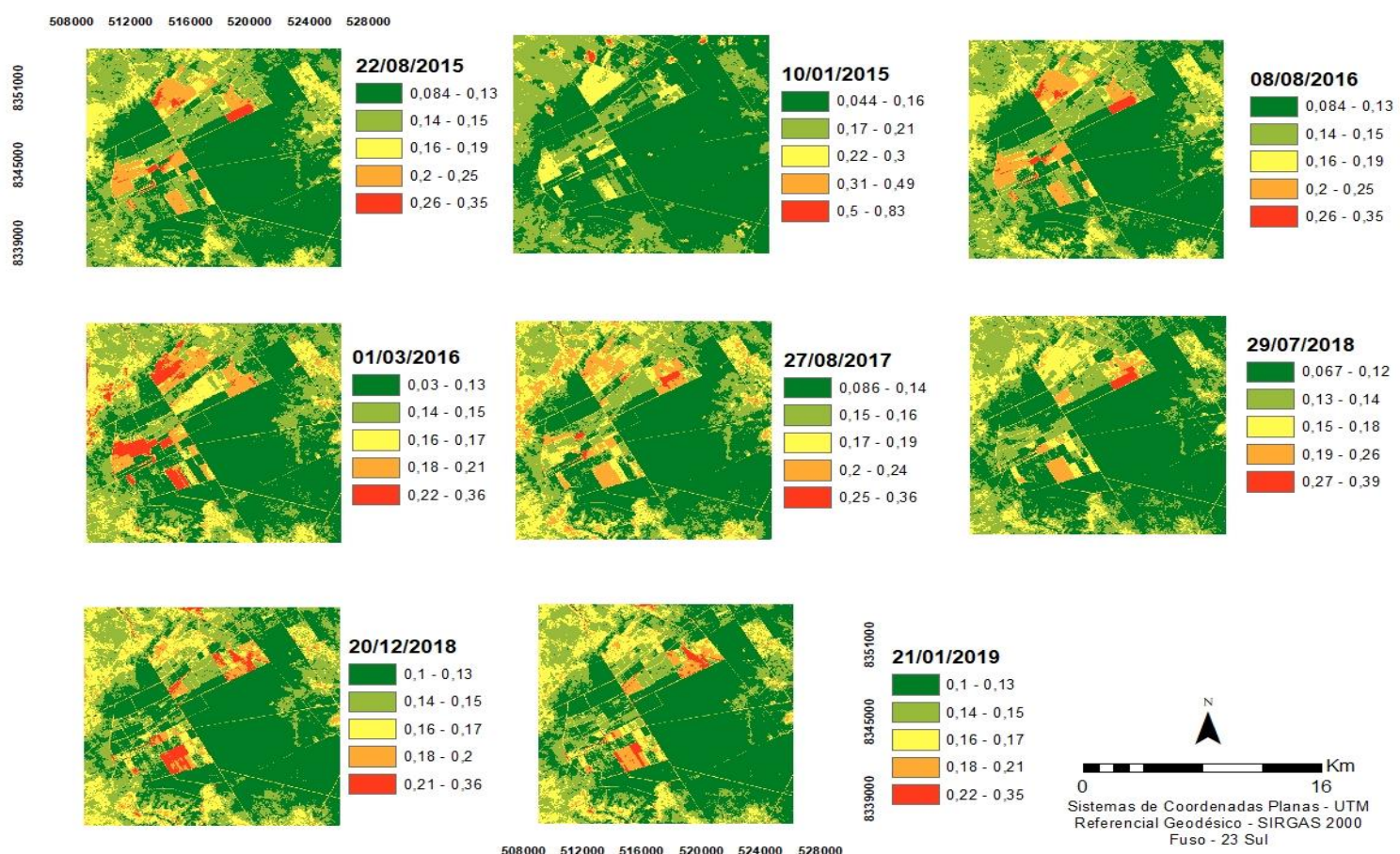

Org.: Os autores, 2019.

Observa-se que os valores de albedo para a área de estudo apresentaram variação entre 0,084 e 0,83. A reflexão de $83 \%$ é em função das nuvens na imagem do dia 10/01/2015, sendo esse resultado relacionado à estação do ano (verão) com grande cobertura de nuvens. As classes que apresentaram menor variação espacial foram as áreas destinadas ao cultivo do eucalipto e as áreas de vegetação nativa de cerrado, com variação entre 0,084 a 0,16.

Figura 3 - Espacialização da Temperatura de superfície.
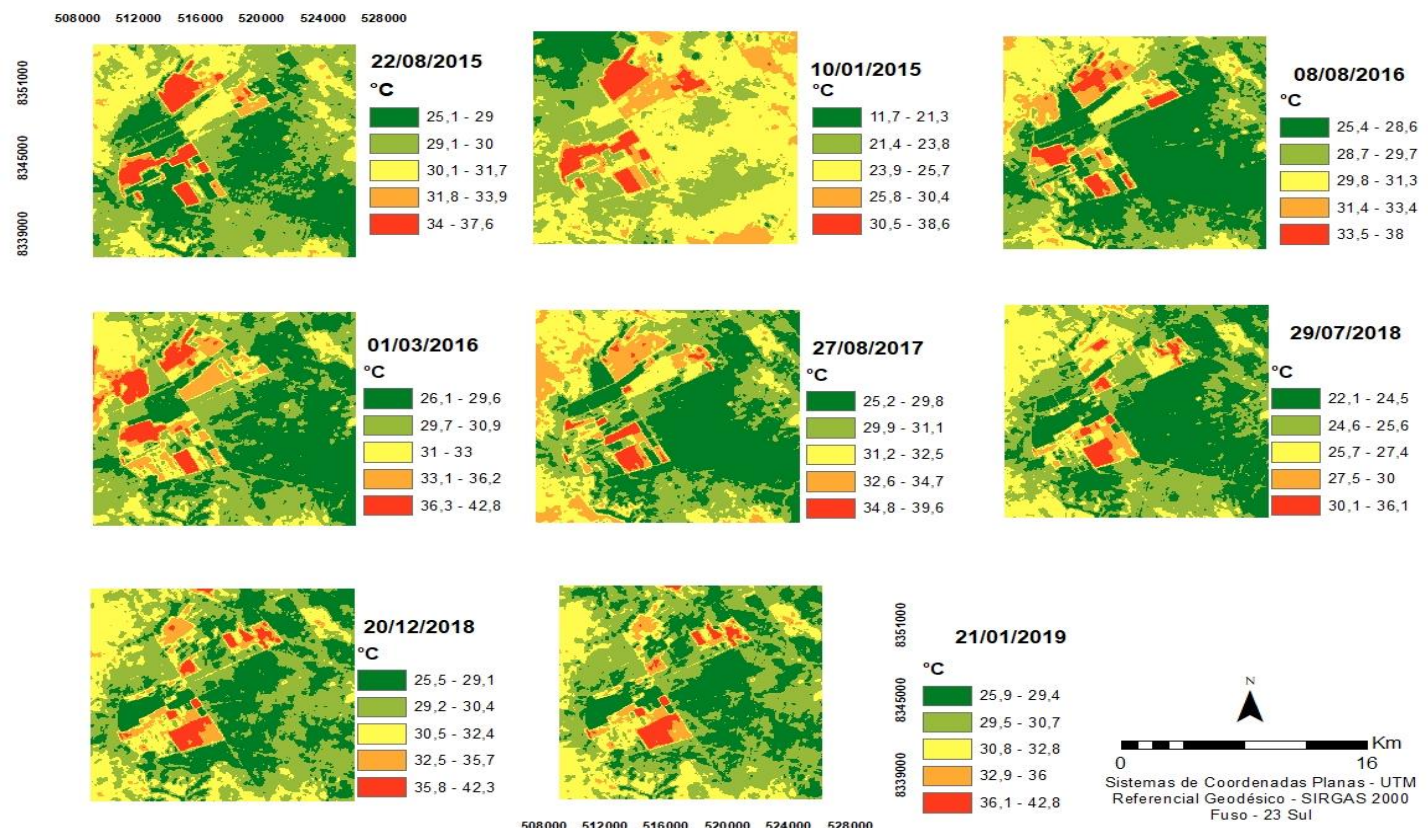

Org.: Os autores, 2019. 
Os valores mais elevados (em vermelho) que apresentaram variação entre 0,21 e 0,39 são em função das áreas de preparo para plantio de eucalipto e pastagens em período seco, no qual esse resultado está associado à baixa cobertura vegetal dessas áreas, apresentando, com isso, alto poder de reflexão.

A temperatura de superfície, como mostra a Figura 3 , dentre os períodos analisados, variou de $11,7^{\circ} \mathrm{C}$ a $42,8^{\circ} \mathrm{C}$, apresentando predominância nos intervalos com baixos valores, sendo $21,3^{\circ}$ a $29,4{ }^{\circ} \mathrm{C}$. Observa-se que os valores de Temperatura de superfície seguem a dinâmica da sazonalidade climática, com valores mais elevados no período úmido e menores no período seco, sendo este resultado associado à disponibilidade de radiação solar incidente, no qual estão apresentados valores significativos no período úmido.

Salienta-se que o valor mínimo estimado para 10/01/2015 reflete o comportamento das nuvens presentes. Intervalos com maiores valores (em vermelho) estão relacionados às áreas de pastagens no período seco e às áreas de preparo para plantio de eucalipto, como ocorreu para o albedo de superfície. Essas áreas apresentaram baixos valores de saldo de radiação, conforme a Figura 4:

Figura 4 - Espacialização do Rn.
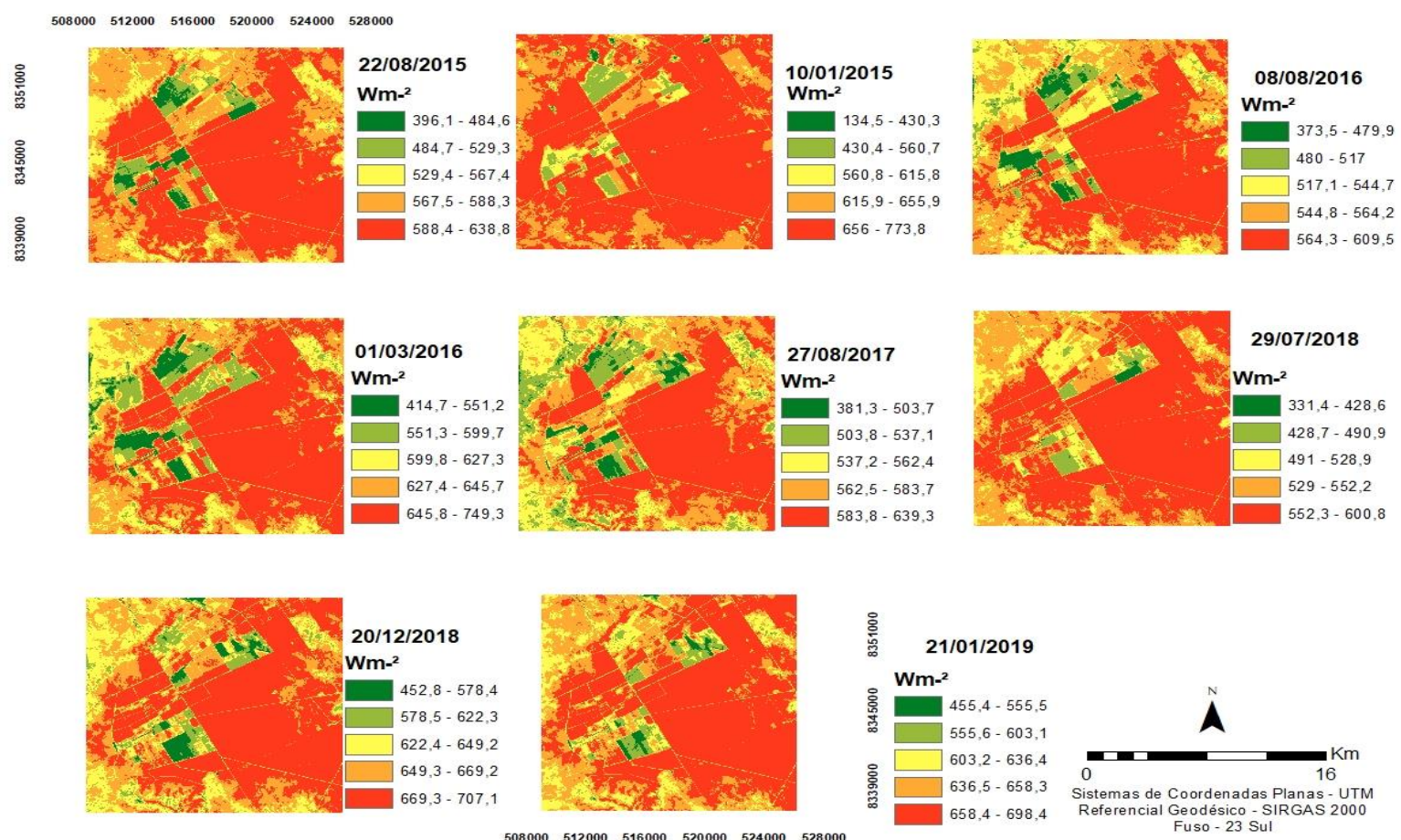

Org.: Os autores, 2019.

É notório que há predominância dos valores mais elevados, sobretudo considerando que há maiores porções de áreas de Cerrado (como visto na seção materiais e métodos). Esses valores variam de 552 $\mathrm{Wm}^{-2}$ a $773,8 \mathrm{Wm}^{-2}$, e os menores valores variaram de $134,5 \mathrm{Wm}^{-2}$ a $578 \mathrm{Wm}^{-2}$, salientando que o valor mínimo é devido à presença de nuvens na área.

\section{Albedo: síntese média dos valores mínimos, médios, máximos e desvio padrão}

Na Figura 5, estão apresentados os valores mínimos, médios e máximos para albedo de superfície para os períodos analisados: 
Figura 5 - Albedo de superfície (mínima, média, máxima e desvio padrão) para os períodos seco e úmido.
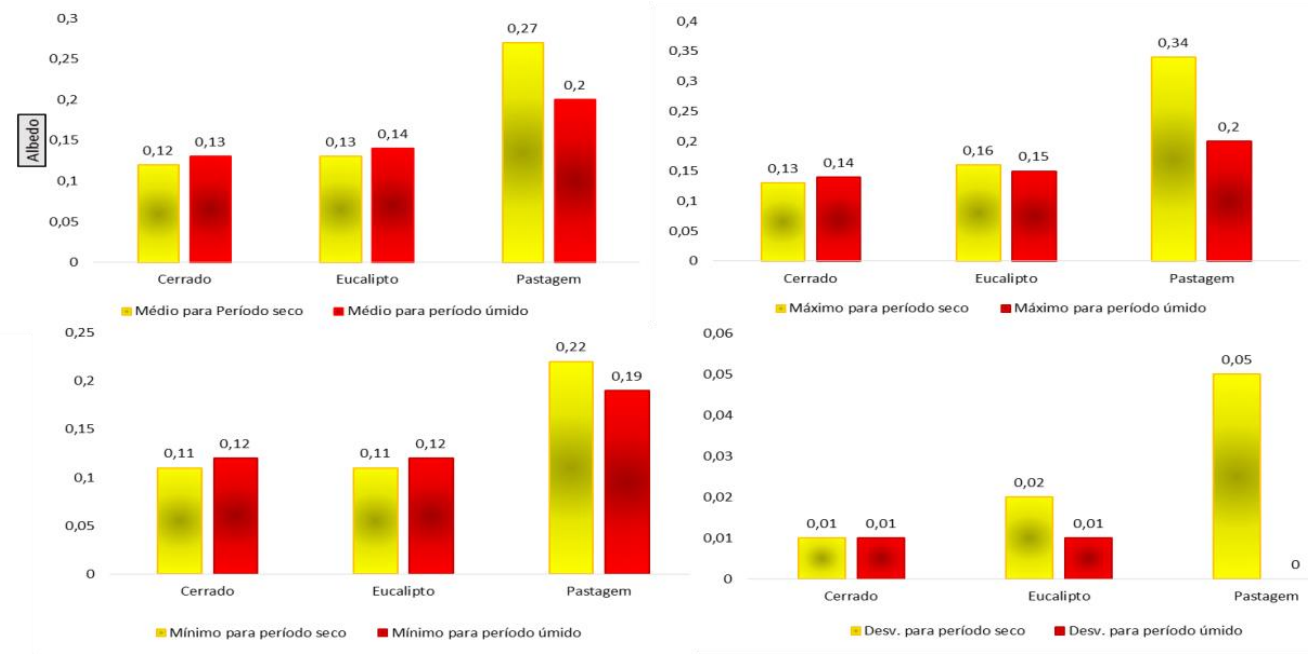

Fonte - Os autores, 2019.

O valor médio de albedo para o Cerrado stricto sensu no período seco foi estimado em $0,12(12 \%)$ e 0,13 para período úmido, tendo baixa variação ao comparar os períodos. Os valores mínimos foram estimados em 0,11 e 0,12 nos períodos úmido e seco, respectivamente, já, para as variações máximas, os valores foram estimados em 0,13 e 0,14 para período seco e úmido. Para o desvio padrão, os valores mostraram baixa variação em relação à média ( 0,1 para período seco e úmido). Ao analisar a literatura científica voltada para as áreas de Cerrado denso, não se encontraram muitos estudos que levassem esta nomenclatura, sendo assim, optou-se em comparar os valores de reflexão com fitofisionomias de áreas de Cerrado, ou seja, generalizando as fitofisionomias. Gomes et al., (2009) encontraram para áreas de Cerrado valores na ordem de $11 \%$ e $12 \%$ nos períodos de 22/02/2005 e 16/07/2005, respectivamente. Já Giongo (2008) encontrou valores médios para áreas de Cerrado computados em $10,5 \%$ e 12,5\%. O autor menciona que Varejão-Silva (2000) aponta que o albedo médio para floresta tropical é de 13\%. Fausto et al., (2016) encontraram valores na ordem de 15\% para áreas de Cerrado e mata ciliar, e, ainda analisando o trabalho desses autores, estes citam que Fausto et al., (2014) encontraram valores de albedo entre 14 e $18 \%$ para áreas de Cerrado e mata ciliar. No trabalho de Leite (2011), o autor analisou 3 períodos, 1985, 1995 e 2010; para 1985, foram verificados valores de albedo de superfície em áreas de Cerrado entre 6,26 e 15,58\%, já, para o período de 1995, a reflexão foi de 6 a 14,5\%, e, em 2010, a reflexão foi 14,89\% durante a passagem do sensor. Nesse sentido, observa-se, na literatura, que os valores encontrados pelos variados autores (e salienta-se que foram analisadas em diferentes condições geofísicas) assemelham-se com os resultados do presente trabalho.

A reflexão para as áreas de eucalipto não apresentou padrão em seus valores, sendo que os mínimos foram estimados em 0,11 e 0,12, nos períodos seco e úmido, respectivamente, com reflexão média de 0,13 no período seco e 0,14 em período úmido, e, quanto aos valores máximos, tem-se 0,16 para o período seco e 0,15 no úmido, e observa-se que não há variação significativa no desvio padrão médio, com 0,02 e 0,01 para período seco e úmido. Como visto em estudo de Querino et al., (2006), o albedo diário seguiu simetria em relação à elevação do Sol, sendo maiores valores de albedo com menor elevação e menores com maior elevação. Isso pode ser explicado sobretudo com discussões astronômicas, visto que, no período denominado de seco, os raios solares estão oblíquos à superfície (tratando-se do hemisfério sul), favorecendo assim a maior reflexão da radiação solar, o que ocorre nos valores máximos de reflexão do eucalipto e para todos os parâmetros estatísticos da pastagem. Em uma outra análise literária, Leitão et al. (2002) menciona o fato da obliquidade dos raios solares, enquanto tiverem menores elevações ao incidirem numa área de vegetação com dossel estruturado não penetram e são refletidos, e, em momentos de verticalidade, penetram e são absorvidos pela vegetação. Ou seja, é necessário compreender fatores geométricos da vegetação. O eucalipto apresentou maiores valores de reflexão ao comparar com o Cerrado, tanto no período seco quanto no úmido nas 3 formas estatísticas analisadas (mínimo, médio e máximo). Isso pode ser justificado por aspectos de coloração do eucalipto, haja visto que na foto-leitura realizada a classe de eucalipto apresentou tonalidades mais claras do que o Cerrado denso, e isso afeta os padrões de reflexão de

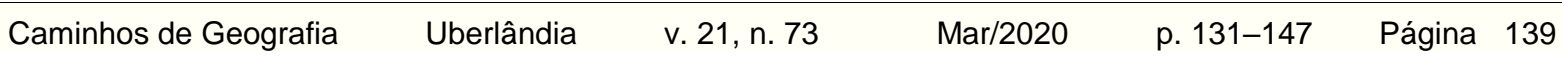


ondas curtas; outro fato pode ser os diferentes estágios de desenvolvimento fenológico do eucalipto. Em análise na literatura, evidenciou-se que Gomes (2009) encontrou valores de albedo para áreas de eucalipto entre 9 e 13\%. No trabalho de Giongo et al., (2009), os valores encontrados são relativamente superiores aos padrões mínimos, médios e máximos desse estudo, sendo entre 19 e 25\%, no entanto, pode ser associado aos fatores fenológicos da plantação; para maiores detalhes, seria necessário um estudo mais específico, sobretudo com dados de campo.

Os valores encontrados para pastagem são interessantes, pois, do ponto de vista analítico, apresentase comportamento sazonal, ou seja, acompanha a dinâmica climática e fenológica. Ao observar o gráfico, fica notório que foi a classe amostral que mais refletiu ondas curtas, isso estando associado aos fatores de coloração, de morfologia e de estrutura da planta, dentre outros.

No que toca às amplitudes, chama-se ainda mais atenção, por haver queda abrupta da reflexão do albedo no período seco para o úmido. A explicação para isso pode ser o fato de que no período seco a pastagem passa por um momento de restrição hídrico (possível estresse hídrico) e suas atividades metabólicas tendem a decrescer, utilizando menores porções de energia e, consequentemente, refletindo-a com maior intensidade; mas, com o input de água no sistema, há uma grande tendência de a pastagem aumentar seus níveis de biomassa e maior atividade fotossintética, e assim utilizando maiores porções de energia do saldo de radiação, refletirá com menor intensidade, como apresentam os valores deste estudo. Os valores médios foram 0,27 e 0,20, no período seco e úmido, já os mínimos foram estimados em 0,22 e 0,19 (períodos seco e úmido), com os valores máximos sendo elevados em demasia ao comparar com os outros usos da terra, sendo estimados em 0,34 e 0,20 para os períodos seco e úmido. Nota-se que o desvio padrão possui variação apenas no período seco, sendo 0,05 . Os valores encontrados nessa pesquisa são próximos aos encontrados por Iziomons e Mayer (2002) em pastagens no sudoeste da Alemanha, sendo entre 22,2 e 36\%. Giongo et al., (2009) computaram valores na ordem de 25 e 34\%. Liberato (2011) encontrou valor médio para áreas de albedo na ordem de $22 \%$, e, este autor citou valores encontrados por Von Randow et al., (2004) na ordem de $20 \%$. Os valores encontrados por Liberato (2011) e Von Randow et al., (2004) são menores que os apresentados por esta pesquisa, no entanto, nas análises de albedo, é preciso compreender a dinâmica espacial, visto que esses autores analisaram áreas na Floresta Amazônica, onde valores de reflexão de ondas curtas tendem a serem menores, isso por causa de fatores meteorológicos e biogeográficos da área.

\section{Temperatura de Superfície: síntese média dos valores mínimos, médios, máximos e desvio padrão}

Na Figura 6, estão dispostos os valores mínimos, médios e máximos para os períodos seco e úmido:

Figura 6 - Temperatura de superfície (mínima, média, máxima e desvio padrão) para os períodos seco e úmido.
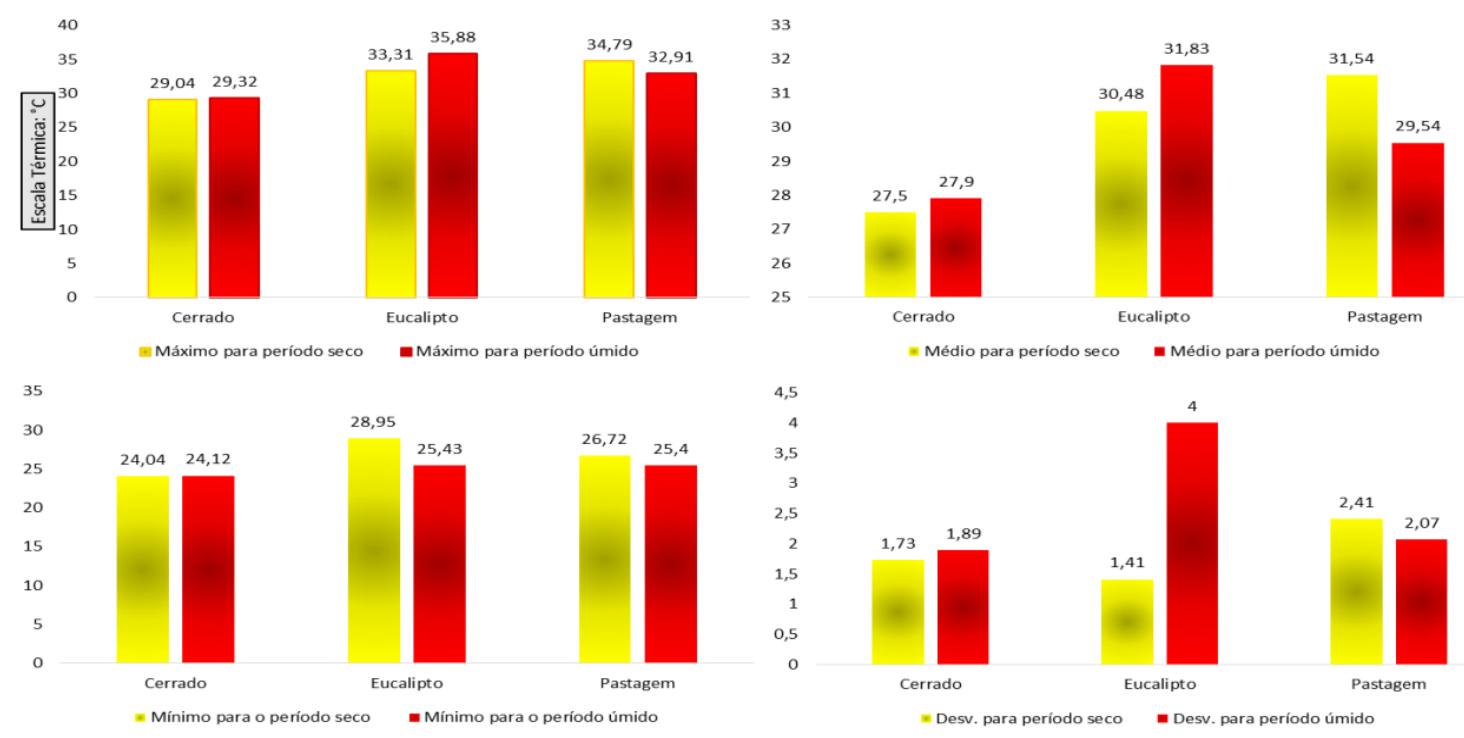

Fonte - Os autores, 2019. 
A temperatura de superfície apresentou valores máximos de $29,04{ }^{\circ} \mathrm{C}$ e $29,32{ }^{\circ} \mathrm{C}$ (período seco e úmido) para a classe de Cerrado, e valores médios estimados em 27,5 e $27,9^{\circ} \mathrm{C}$, respectivamente para período seco e úmido, já os valores mínimos foram medidos em 24,04 (período seco) e $24,12{ }^{\circ} \mathrm{C}$ (período úmido). Dentre as classes analisadas, o Cerrado stricto sensu apresentou as menores medidas termais (mínimas, médias e máximas), além disso, apresentou a menor variação dos valores em relação à média. Fica evidente que a variação da temperatura de superfície segue a dinâmica da sazonalidade climática, obtendo elevações no campo térmico no período úmido, em que há maior elevação do Sol, propiciando a incidência de radiação de maneira intensa. Em estudos realizados no Bioma Cerrado, foram encontrados valores entre $25^{\circ} \mathrm{C}$ e $45^{\circ} \mathrm{C}$ (SANTOS et al., 2011; FAUSTO et al., 2016; CAIONI et al., 2017).

Em relação ao comportamento de médias menos elevadas nas áreas de Cerrado, é oportuno mencionar a funcionalidade fenológica, tendo em vista o consumo hídrico/evapotranspiração dessa fitofisionomia (MARTINS e ROSA, 2019), que tende a umedecer a superfície foliar e decrescer o campo térmico. Outra explicação para esse decréscimo pode ser entendida por meio das concepções de modelos teóricos de leis da radiação; dentre eles pode-se citar a percepção do físico Kirchhoff, que remete à emissividade termal de um dado corpo (JENSEN, 2011). Dessa forma, áreas de vegetação apresentam altas emissividades termais, indicando que a vegetação emite mais radiação térmica nos ambientes adjacentes e, consequentemente, sua temperatura decresce. Nessa lógica, fica evidente que os dados precisam ser analisados de maneira integrada, ou seja, é preciso compreender o fenômeno (balanço de radiação) como um todo, desde entrada, perdas e repartição.

Em relação às áreas de eucalipto, essas apresentaram valores mínimos de 28,95 e $25,43^{\circ} \mathrm{C}$ (período seco e úmido, respectivamente), e valores médios estimados em 30,48 e $31,83^{\circ} \mathrm{C}$ (período seco e úmido), no qual os valores máximos seguiram a variação da sazonalidade climática, com valores mais acentuados no período úmido $\left(35,88^{\circ} \mathrm{C}\right)$ e a menor média no período seco $\left(33,31^{\circ} \mathrm{C}\right)$. A variação dos valores em relação à média (desvio padrão) foi mais acentuada no período úmido, sendo $4{ }^{\circ} \mathrm{C}$ e 1,41 -C para o período seco. Alguns estudos mostram que as médias térmicas para áreas de eucalipto variam entre $11,5^{\circ} \mathrm{C}$ e $19,44^{\circ} \mathrm{C}$ (MASHIKI e CAMPOS, 2013; LEITE et al., 2012). É salutar mencionar que os valores encontrados nesse estudo, mesmo tendo comportamento simétrico com a dinâmica astronômica, destoa em relação à literatura, e isso se justifica pela proximidade de extensões de áreas de preparo para plantio de eucalipto, que possuem campo térmico mais elevado, tendendo a transferir calor para áreas de eucalipto.

Em áreas de pastagens, a temperatura mínima foi estimada em $26,72{ }^{\circ} \mathrm{C}$ e $25,4{ }^{\circ} \mathrm{C}$ (período seco e úmido, respectivamente), com valor médio para período seco em $31,54^{\circ} \mathrm{C}$ e $29,54^{\circ} \mathrm{C}$ no úmido, e com máximos estimados em 34,79 e $32,91^{\circ} \mathrm{C}$ (período seco e úmido), apresentando variação de 2,41 e $2,07^{\circ} \mathrm{C}$ em relação à média (em período seco e úmido, respectivamente). Estudos para ambientes de pastagens mostraram que a temperatura de superfície pode variar entre $22,6{ }^{\circ} \mathrm{C}$ e $31,4^{\circ} \mathrm{C}$ (SALLO et al., 2014; PAVÃO et al., 2017).

Observa-se que os valores no campo térmico não seguem a lógica astronômica, tendo valores mais elevados no período seco e menores no úmido, e, isso pode ser justificado ao passo que em função da deficiência hídrica há secagem rápida da gramínea forrageira, e isso tende a elevar sistematicamente o campo térmico, haja vista que a radiação incidente (onda curta) tenderá a ser utilizada para fenômenos de aquecimento vertical do solo (PRIMAVESI et al., 2007). No período úmido, com o incremento de água no solo, há maiores porções de biomassa na pastagem, e isso favorece o uso da energia para a transferência de massa/vapor para as camadas adjacentes da atmosfera.

\section{Saldo de Radiação: síntese média dos valores mínimos, médios, máximos e desvio padrão}

$\mathrm{Na}$ Figura 7, estão representados os valores estatísticos para o saldo de radiação nos períodos seco e úmido nas amostras coletadas.

$\begin{array}{lllll}\text { Caminhos de Geografia } \quad \text { Uberlândia } & \text { v. 21, n. 73 } & \text { Mar/2020 } & \text { p. 131-147 Página } 141\end{array}$


Figura 7 - Saldo de Radiação (mínima, média, máxima e desvio padrão) para os períodos seco e úmido.
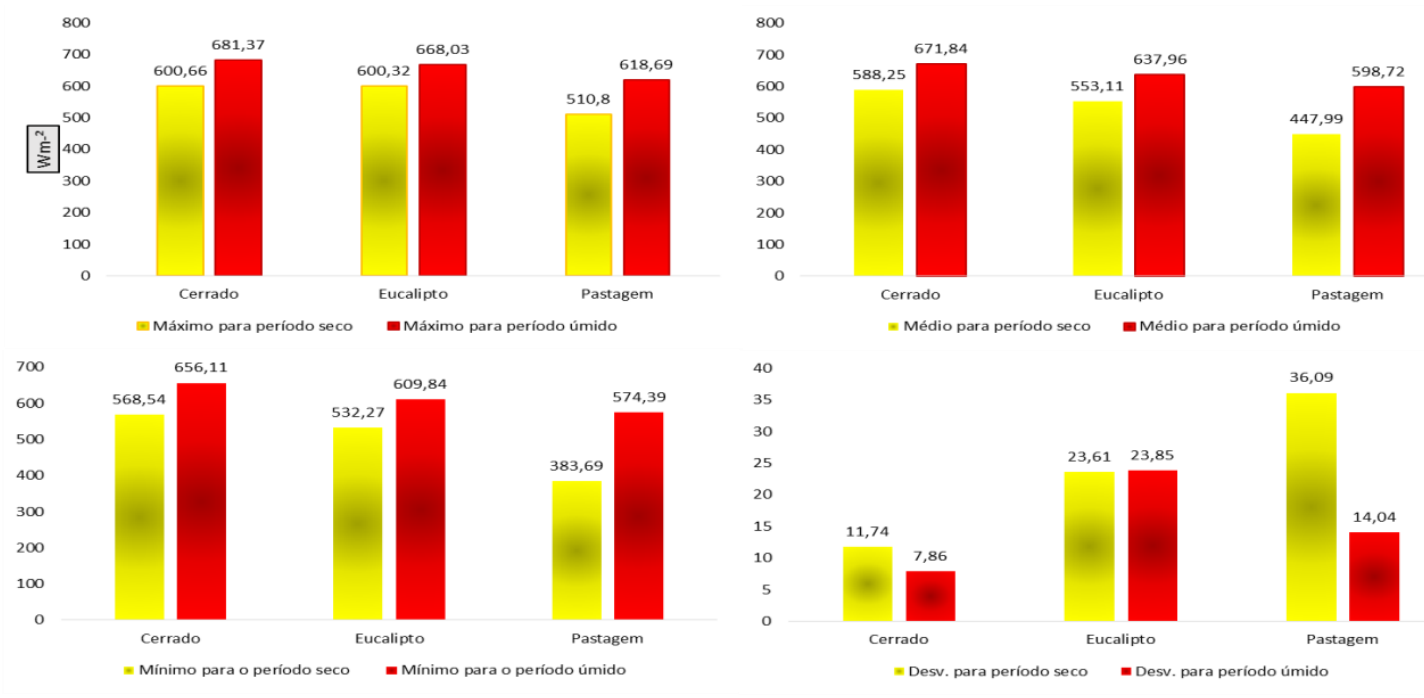

Fonte - Os autores, 2019.

Nas áreas de Cerrado, os valores mínimos de saldo de radiação foram estimados em $568,64 \mathrm{Wm}-^{2} \mathrm{e}$ $656,11 \mathrm{~W}-2$ para os períodos seco e chuvoso, e os valores médios estimados em $588,25 \mathrm{Wm}^{-2}$ e 671 , $84 \mathrm{Wm}^{-2}$ (período seco e úmido), assim o saldo de radiação máximo foi estimado em $600,06 \mathrm{Wm}^{-2} \mathrm{e}$ $681,37 \mathrm{Wm}^{-2}$ (período seco e úmido). O desvio padrão foi calculado em 11,74 e 7,86 Wm-2 para os períodos seco e úmido. Para o Cerrado, o Rn apresentou-se maiores em relação aos outros usos da terra analisados, isso está relacionado à atividade biofísica - fotossíntese e evapotranspiração - dessa fitofisionomia, tendo variação sazonal, principalmente em função da disposição hídrica no solo, em que o decréscimo reduz a evapotranspiração e consequentemente a demanda de fluxo de calor latente. Os valores de albedo e de temperatura de superfície foram relativamente menos elevados (conforme visto nos itens anteriores), e consequentemente as ondas longas (embasando na lei de Stefan-Boltzmaan (LEITÃO, 1994) de um corpo negro emitir fluxo radiante conforme absorção de temperatura, e na lei de deslocamento de Wien (VAREJÂO-SILVA, 2006), sabendo-se que a Terra, por ter temperatura média de $300 \mathrm{~K}$, emite radiação de ondas longas) emitidas pela superfície foram menores, o que tendeu a acrescer a radiação no ambiente. Estudos avaliando $\mathrm{Rn}$ em ambientes de Cerrado apontaram que pode variar de 510,1 Wm-2 a $622 \mathrm{Wm}^{2}$ (SALLO et al., 2014; PAVÃO et al., 2016; PAVÃO et al., 2017).

Nas áreas de eucalipto, o Rn mínimo para período seco e úmido foi mensurado em 532,27 e Wm-2, respectivamente. Os valores médios foram estimados em $553,11 \mathrm{Wm}^{-2}$ e $637,96 \mathrm{Wm}^{-2}$ (período seco e úmido), e os valores para Rn máximo foram de 600,32 e 668,03 Wm-2, com desvio padrão médio calculado em 23,61 e 23,85 $\mathrm{Wm}^{2}$ para período seco e úmido, respectivamente. Seguindo o raciocínio da emissão de ondas longas, menciona-se que as médias térmicas do eucalipto (elevadas) influenciaram o Rn, sobretudo decrescendo (FREY et al., 2007; FAUSTO et al., 2016). O albedo de superfície não influenciou no decréscimo, haja vista que não apresentou variação significativa. Em áreas de eucalipto, o Rn em outros estudos tendeu a variar entre $420,12 \mathrm{Wm}^{-2}$ e a $780 \mathrm{Wm}^{-2}$ (GOMES et al., 2009; MENEZES et al., 2011; FURLAN et al., 2011).

Nas áreas de pastagens, os valores mínimos de Rn foram estimados em $383,69 \mathrm{Wm}^{-2}$ e $574,39 \mathrm{Wm}-{ }^{2}$ (período seco e úmido, respectivamente), com valores médios para período seco e úmido de 447,99 e $598,72 \mathrm{Wm}^{-2}$ e 510,8 e $618,69 \mathrm{Wm}^{-2}$ de valores máximos, o desvio padrão em relação à média foi mensurado em $36,09 \mathrm{Wm}^{-2}$ para o período seco e $14,04 \mathrm{Wm}^{-2}$ no período úmido. O $\mathrm{Rn}$ da pastagem foi o que sofreu influência significativa tanto da temperatura de superfície, quanto do albedo, visto que houve maior reflexão de ondas curtas e maior emissão de ondas longas da superfície, alterando sobremaneira a energia em saldo. Observa-se que há diferença significativa do período seco para úmido, no que toca à disponibilidade de energia, nos valores mínimos, médios e máximos, isso estando associado à diferença do conteúdo de biomassa presente, sendo predominante no período úmido e escasso no período seco (VELOSO, 2018). É oportuno mencionar que a substituição de floresta em pastagens decresce o Rn (VON RONDOW et al., 2004; LIBERATO e CARDOSO, 2011). Estudos

$\begin{array}{lllll}\text { Caminhos de Geografia } & \text { Uberlândia } & \text { v. 21, n. 73 } & \text { Mar/2020 } & \text { p. 131-147 }\end{array}$


apontam que em ambientes de pastagens o $\mathrm{Rn}$ pode variar entre $451 \mathrm{Wm}^{-2}$ e $524,1 \mathrm{Wm}-{ }^{2}$ (OLIVEIRA e MORAES, 2013; UDA et al., 2013).

\section{VALIDAÇÃO: COMPARAÇÃO ENTRE TS E TAR}

Para validação dos dados, recorreu-se à mensuração da diferença entre a temperatura do ar (fornecida pelo INMET) e a temperatura de superfície (Tabela 3):

Tabela 3 - Validação dos dados obtidos.

\begin{tabular}{cccc}
\hline Datas & $\begin{array}{c}\text { Temperatura de } \\
\text { superfície }\end{array}$ & Temperatura do ar & Diferença \\
\hline $10 / 01 / 2015$ & 22,55 & 29,07 & 6,52 \\
$22 / 08 / 2015$ & 27,31 & 28,8 & 1,49 \\
$01 / 03 / 2016$ & 26,16 & 30,8 & 4,64 \\
$08 / 08 / 2016$ & 28,93 & 28,7 & 0,23 \\
$27 / 08 / 2017$ & 29,6 & 26 & 3,6 \\
$29 / 07 / 2018$ & 26,09 & 27,4 & 1,31 \\
$20 / 12 / 2018$ & 29,06 & 29 & 0,06 \\
$20 / 01 / 2019$ & 29,65 & 32,2 & 2,55 \\
\hline
\end{tabular}

Fonte - Os autores, 2019. INMET, 2019.

Os dados obtidos pelo algoritmo SEBAL apresentam-se com boa consistência, tendo diferença destoante apenas para duas imagens (10/01/2015 e 01/03/2016) ao comparar com os dados da estação meteorológica. Chama-se atenção pelo fato de o sensor detectar o alvo (pixel da estação) a $705 \mathrm{KM}$ de altitude e aproximar-se tanto do valor de referência, exceto para os períodos mencionados.

\section{CONSIDERAÇÕES FINAIS}

No tocante aos resultados deste estudo, observou-se dinâmica intrínseca das variáveis meteorológicas com a sazonalidade climática da região. Além disso, foi observada forte influência do albedo e da temperatura de superfície no saldo de radiação nos diferentes usos da terra.

Do ponto de vista operacional, o presente trabalho foi realizado com dados de fácil acesso e manipulação, sendo atrativos para novos estudos no âmbito da ciência geográfica. Chama-se atenção para novos estudos que envolvam análises de emissividades para os diferentes usos da terra, para mostrar com maior precisão a influência do uso e da cobertura da terra no balanço de radiação.

Quanto à validação científica dos dados, é importante destacar que os dados se mostraram consistentes, com pequenas diferenças ao comparar com os dados de referência em superfície, ou seja, os dados do INMET; e tais diferenças são aceitáveis. Isso porque trata da temperatura radiante dos objetos na superfície que envolve o fluxo de radiância, a emissividade termal sob o prisma da banda 10 (para o TIRS) e algumas constantes teóricas abarcadas nas concepções da física.

Diante disso, este estudo pode contribuir para a comunidade científica, no que tange à dinâmica da ocupação do solo e aos componentes do balanço de radiação à superfície e à atmosfera.

\section{REFERÊNCIAS BIBLIOGRÁFICAS}

ALMEIDA, J.W.L. Métodos de sensoriamento remoto no mapeamento de Veredas na APA Rio Pandeiros. Universidade Federal de Minas Gerais, UFMG, 2016. Dissertação de mestrado. p.91.

ALLEN, R. G., TASUMI, M. AND TREZZA, R. SEBAL (Surface Energy Balance Algorithms for Land) Advanced Training andUsers Manual - Idaholmplementation, version 1.0, 97 p., 2002.

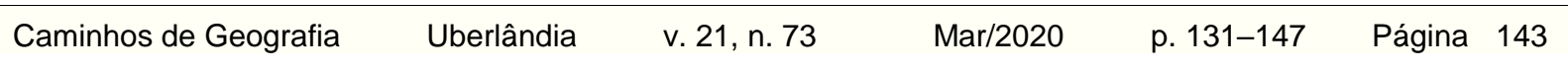


ALVES, L. E. R.; GOMES, H. B.; SANTOS, M. N.; FREITAS, I. G. F. Balanço De Radiação Através Do Satélite Landsat-8 Na Bacia Do Rio Pajeú. Revista Do Departamento De Geografia, v. 33, p. 117127, 2017. https://doi.org/10.11606/rdg.v33i0.124577

ANTUNES, F. Z. Caracterização climática. Informe Agropecuário, Belo Horizonte, v.17, n. 181, p. 1519, 1994.

ATAÍDE, Kleber Renato da Paixão. Modelagem de determinação da evapotranspiração real para o bioma Cerrado por meio de dados de sensoriamento remoto orbital. Universidade de Brasília, Brasília, 2017. Dissertação de Mestrado. p.176.

BEZERRA, B.G. Balanço de energia e evapotranspiração com diferentes tipos de coberturas do solo no Cariri Cearense através do algoritmo SEBAL. 2006. Dissertação (mestrado em Meteorologia). Unidade Acadêmica de ciências atmosféricas, UFCG, 2006.

BEZERRA, Bergson Guedes; SILVA, B. B. da ; FERREIRA, Nelson Jesus . Estimativa da evapotranspiração diária utilizando-se imagens digitais TM - Landsat 5. Revista Brasileira de Meteorologia, v. 23, p. 305-317, 2008. https://doi.org/10.1590/S0102-77862008000300005

BOWEN, IS. The ratio of heat tosses by conduction and by evaporation from any water surface. Phys. Rev. Sei. 2, 27:779-87, 1926. https://doi.org/10.1103/PhysRev.27.779

CAIONI, CHARLES; NEVES, S. M. A. S.; COCHEV, J. S. Análise da temperatura aparente dos elementos da paisagem da microbacia Pedra do Índio em Alta Floresta-MT. SEMINA. CIÊNCIAS EXATAS E TECNOLÓGICAS (ONLINE), v. 39, p. 11-18, 2018.

CARVALHO, Hudson de Paula; DOURADO NETO, D.; TEODORO, Reges Eduardo Franco; MELO, Benjamim de. Balanço hídrico climatológico, armazenamento efetivo da água no solo e transpiração na cultura de café. Bioscience Journal (Online), v. 27, p. 221-229, 2011. https://doi.org/10.5433/16790375.2018v39n1p11

CONCEIÇÃO, Adriana Fantinati. Balanço de energia da superfície nas bacias hidrográficas dos rios Cachoeira e Atibainha do Sistema Cantareira por meio de sensoriamento remoto. Universidade Estadual de Campinas, Instituto de Geociências, Campinas, SP, 2018. Dissertação de Mestrado. p.167.

DEBASTIANI, A. B.; SA, E. A. S.; MARTINS NETO, R. P.; SCHIMALSKI, M. B. Mapeamento do saldo de radiação no Parque Nacional de São Joaquim - SC. Advances in Forestry Science, v. 5, p. 363367, 2018.

FAUSTO, M. A.; ANGELINI, L. P.; MARQUES, H. O. ; SILVA FILHO, A.; MACHADO, N. G.; BIUDES, M. S. Impactofland-use change in the net radiationofthe Cerrado ofthesouthern Mato Grosso. Revista Ambiente e Agua, v. 11, p. 350, 2016. https://doi.org/10.4136/ambi-agua.1843

FAUSTO, M. A.; MACHADO, N. G.; NOGUEIRA, J. S.; BIUDES, M. S. Net radiationestimatedbyremotesensing in Cerrado areas in theUpperParaguay River Basin. JournalofApplied Remote Sensing, v. 8, p. 1-17, 2014. https://doi.org/10.1117/1.JRS.8.083541

FIETZ, C. R.; FISCH, G. F. Avaliação de modelos de estimativa do saldo de readiação e do método de Pristley-Taylor para a região de Dourados, MS. Revista Brasileira de Engenharia Agrícola e Ambiental, v. 13, p. 449-453, 2009. https://doi.org/10.1590/S1415-43662009000400012

FREY, C. M.; RIGO, G.; PARLOW, E. Urbanradiation balance oftwocoastalcities in a hot Anddryenvironment. International Journalof Remote Sensing, v. 28, p. 2695-2712, 2007. http://dx.doi.org/10.1080/01431160600993389

FURLAN, Deise Nunes; BALLESER, M. V. R.; ANDRADE, R. G. Estimativa dos valores de saldo de radiação e fluxo de calor no solo em diferentes condições antrópicas na bacia do rio Ji-Paraná, Rondônia. In: simpósio Brasileiro de Sensoriamento Remoto, 2011, Curitiba. Simpósio Brasileiro de Sensoriamento Remoto, 2011.

GIANOTTI, A. R. C.; SOUZA, MARIA J. H.; MACHADO, E. L. M.; PEREIRA, I. M; VIEIRA, A. D.; MAGALHÃES, M. R. Análise microclimática em duas fitofisionomias do Cerrado no Alto Vale do Jequitinhonha, Minas Gerais. Revista Brasileira de Meteorologia (Impresso), v. 28, p. 246-256, 2013. https://doi.org/10.1590/S0102-77862013000300002 
GIONGO, P. R.; Estimativa do balanço de radiação com técnicas de sensoriamento remoto e dados de superfície. Universidade Federal Rural de Pernambuco, 2008. Dissertação de mestrado em Engenharia Agrícola. p. 92.

GOMES, H.B.; Balanço de Radiação e energia em Áreas de cultivo de cana-de-açúcar e Cerrado no estado de São Paulo mediante imagens orbitais. Universidade Federal de Campina Grande, 2009. Tese de doutorado em Meteorologia, p.108.

GOMES, H. B.; SILVA, B. B.; CAVALCANTI, E. P.; Rocha, H. R. Balanço De Radiação Em Diferentes Biomas no Estado de São Paulo Mediante Imagens Landsat 5. UNESP, Geociências, v. 28, n. 2, p. 153-164, 2009.

HELDWEIN, Arno Bernardo; MALDANER, Ivan Carlos; BOSCO, Leosane Cristina; TRENTIN, Gustavo; Grimm, Edenir Luis; RADONS, Sidinei Zwick; LUCAS, Dionéia Daiane Pitol . Saldo de radiação diurno em dosséis de batata como função da radiação solar global. Revista ciência agronômica (UFC. Online), v. 43, p. 96-104, 2012. https://doi.org/10.1590/S1806-66902012000100012

IZIOMONS, M. G.; MAYER, H. On the variability and modeling of surface albedo and long-wave radiation componenTemperatura de superfície . Agricultural and Forest Meteorology, v.111, p.141152, 2002. https://doi.org/10.1016/S0168-1923(02)00013-8

JENSEN, J. R. Sensoriamento remoto do ambiente: uma perspectiva em recursos terrestres.Tradução de José Carlos Neves Epiphanio (coord.). [et al.]. 2. ed. São José dos Campos:Parêntese, 2011. 672 p.

JESUS, T. C. L.; SENNA, M. C. A.; CATALDI, M. ; PAIVA, C. M. ; FRANZ, B. Impacto Do Aumento Da Concentração Atmosférica De Co2 No Balanço Hídrico Climatológico Do Cerrado. Revista Brasileira de Climatologia, v. 21, p. 313-326, 2017. https://doi.org/10.5380/abclima.v21i0.46432

JUNG, L. H.; BISCARO, G. A.; OLIVEIRA, G. Q.; ALVES, M. A.; GIACON, G. M. Estimativa da evapotranspiração de referência em uma região do Alto Pantanal. MAGISTRA CRUZ DAS ALMASBA, v. 28, p. 168-177, 2016.

LEITÃO, M. M. V. B. R. Balanço de Radiação em três ecossistemas da Floresta Amazônica: campina, campinara na e mata densa. Dissertação de Mestrado em Meteorologia - São Jose dos Campos, SP. Instituto Nacional de Pesquisas Espaciais - INPE. 135p., 1994.

LEITE, M. E.; BRITO, J.L.S. Sensoriamento Remoto Aplicado À Análise Temporal da Relação Uso da Terra / Temperatura e Albedo de Superfície na Bacia do Rio Vieira No Norte De Minas Gerais. Revista Brasileira de Climatologia, v. 10, p. 98, 2012. https://doi.org/10.5380/abclima.v10i1.30590

LEITE, M.E.; FONSECA, G. S.; SILVA, L.A.; LEITE, M. R. Geotechnologies applied to the surface temperature estimation in different soil uses and occupations in the environmental protection area of the Rio Pandeiros - Minas Gerais. CADERNO DE GEOGRAFIA, v. 28, p. 490-509, 2018. https://doi.org/10.5752/P.2318-2962.2018v28n53p490-509

LIBERATO, A. M. Albedo À Superfície a partir de imagens landsat 5 - TM em Áreas De Floresta e Pastagem na Amazônia. Revista de Geografia (UFPE) V. 28, No. 1, 2011.

MARTINS, A. P.; ROSA, R. Estimativa de evapotranspiração real a partir de imagens do sensor MODIS/AQUA e do algoritmo SEBAL na bacia do Rio Paranaíba - Brasil. CADERNO DE GEOGRAFIA, v. 29, p. 351-367, 2019. https://doi.org/10.5752/P.2318-2962.2019v29n57p351-367

MARTINS, A. L.; CUNHA, C. R. ; PEREIRA, V. M. R. ; DANELICHEN, VICTOR HUGO DE MORAIS ; MACHADO, N. G. ; LOBO, F. A. ; DE MUSIS, C. R. ; BIUDES, MARCELO SACARDI .Mudanças em índices biofísicos devido à alteração da cobertura do solo em área nativa de Cerrado em Mato Grosso. Ciência e Natura, v. 37, p. 152-159, 2015. https://doi.org/10.5902/2179460X16145

MASHIK, M.Y.; CAMPOS, S. Influência do Uso e Ocupação do Solo na Temperatura Aparente Da Superfície No Município De Botucatu/Sp. Energ. Agric., Botucatu, vol. 28, n.3, p.143-149, julhosetembro, 2013. https://doi.org/10.17224/EnergAgric.2013v28n3p143-149

MENEZES, S. J. M. da Costa. Evapotranspiração regional utilizando o SEBAL em condições de relevo montanhoso. Universidade Federal de Viçosa. Dissertação de mestrado em engenharia agrícola. Viçosa, 2006. p.84. 
MONTEIRO, H.C. Uso da terra e variações de temperatura e umidade relativa do ar na bacia do Córrego Marinheiro, Sete Lagoas - MG. Universidade Federal de Minas Gerais. Dissertação de Mestrado. Belo Horizonte, 2016. p. 140.

NÓBREGA, R. S. Impactos do desmatamento e de mudanças climáticas nos recursos hídricos na Amazônia Ocidental utilizando o modelo Slurp. Revista Brasileira de Meteorologia (Impresso), v. 29, p. 111-120, 2014. https://doi.org/10.1590/0102-778620130024

OLIVEIRA, GABRIEL DE; MORAES, ELISABETE CARIA. Validação do balanço de radiação obtido a partir de dados MODIS/TERRA na Amazônia com medidas de superfície do LBA. Acta Amazonica (Impresso), v. 43, p. 353-363, 2013. https://doi.org/10.1590/S0044-59672013000300011

OLIVEIRA, Leidjane Maria Maciel de; MONTENEGRO, S. M. G. L.; SILVA, B. B.; MOURA, A. E. S. S. Balanço De Radiação Por Sensoriamento Remoto Em Bacia Hidrográfica Da Zona Da Mata Nordestina. Revista Brasileira de Meteorologia (Impresso), v. 30, p. 16-28, 2015. https://doi.org/10.1590/0102778620130652

PAVÃO, V. M.; NASSARDEN, D. C. S.; PAVÃO, L. L.; MACHADO, N. G.; BIUDES, M. S. Impacto da Conversão da Cobertura Natural em Pastagem e Área Urbana sobre Variáveis Biofísicas no Sul do Amazonas. Revista Brasileira de Meteorologia, v. 32, p. 343-351, 2017. https://doi.org/10.1590/0102$\underline{77863230002}$

PAVÃO, V.M.; QUERINO, C. A. S.; BENEDITTI, C. A.; PAVAO, L. L.; QUERINO, J. K. A. S.; MACHADO, N. G.; BIUDES, M. S. Variação Espacial e Temporal do Saldo de Radiação Superficial em uma Área do Sul do Amazonas, Brasil. Revista Ra'e Ga Espaço Geográfico em Análise, v. 2, p. 333, 2016. https://doi.org/10.5380/raega.v37i0.42469

PRIMAVESI, O.; ARZABE, C.; PEDREIRA, M.S.; Mudanças climáticas: visão tropical integrada das causas, dos impactos e de possíveis soluções para ambientes rurais ou urbanos. São Carlos: Embrapa Pecuária Sudeste, 2007.

PAULA, M. R.; Cabral, J.B.P; MARTINS, A. P. Uso De Técnicas de Sensoriamento Remoto e Geoprocessamento na Caracterização do Uso da terra da Bacia Hidrográfica da UHECaçu-Go. Revista GeoNorte, v. 4, p. 1482-1490, 2012.

PEREIRA, PRISCILA LIMA; RODRIGUES, HERNANI JOSÉ BRAZÃO. Análise e estimativa dos componentes do balanço de energia em ecossistema de manguezal amazônico. Revista Brasileira de Meteorologia (Impresso), v. 28, p. 75-84, 2013. https://doi.org/10.1590/S0102-77862013000100008

PEREIRA, J. A. S.; TAVARES JUNIOR, J. R. Classificação Supervisionada e Saldo de Radiação para Discriminação de Alvos De Superfície no Entorno Do Reservatório de Itaparica - Pe. Rbc. Revista Brasileira De Cartografia (Online), v. 69, p. 1211-1222, 2017.

REIS, M. G.; RIBEIRO, A; BAESSO, R. C. E.; SOUZA, W. G.; FONSECA, S.; LOOS, R. A. Balanço hídrico e de energia para plantios de eucalipto com cobertura parcial do solo. Ciência Florestal (UFSM. Impresso), v. 24, p. 117-126, 2014. https://doi.org/10.5902/1980509813329

SALLO, FERNANDO DA SILVA; DE FRANÇA, MAURO SÉRGIO; DE MORAIS, DENES MARTINS; RODRIGUES, RODICRISLLER; BIUDES, MARCELO SACARDI. Estimativa de componentes do balanço de radiação em diferentes tipos de uso e cobertura do solo. Revista Ambiente \& Água, v. 9, p. 347-358, 2014. https://doi.org/10.4136/ambi-agua.1273

SANTOS NICALI BLEYER; L.G.FERREIRA; FERREIRA, C. NILSON. Padrões De Distribuições Espaciais E Temporais De Temperaturas Associados Ao Bioma Cerrado. Mercator (UFC), v. 10, p. 189-204, 2011. https://doi.org/10.4215/RM2011.1021.0013

SANTOS, C. A. C.; Nascimento, R. L.; ARAUJO, A. L.; BEZERRA, B. G. Obtenção do saldo de radiação em áreas de pastagem e floresta na amazônia (estação seca) através do sensor MODIS. Revista Brasileira de Meteorologia (Impresso), v. 29, p. 420-432, 2014. https://doi.org/10.1590/0102$\underline{778620130591}$

SEEG. Estimativas de Emissões de Gases de Efeito Estufa. Disponível em: http://www.observatoriodoclima.eco.br/wp-content/uploads/2018/11/PPT-SEEG-6-LANCAMENTOGERAL-2018.11.21-FINAL-DIST-compressed.pdf. Acesso em: 10 de março de 2019. 
SILVA, B. B. da, LOPES, G. M.; AZEVEDO, P. V. de. Balanço de radiação em áreas irrigadas utilizando imagens Landsat 5 TM. Revista Brasileira de Meteorologia, v.20, n.2. p.243-252, 2005.

SILVA, L.A.P. Sensoriamento Remoto Aplicado a Análise do Consumo Hídrico de Diferentes Usos da Terra. Universidade Estadual de Montes Claros. Trabalho de Conclusão de Curso. p. 63. 2018.

SILVA, Luiz Carlos da; CUNHA, José Maurício da; MACHADO, Nadja Gomes; BIUDES, Marcelo Sacardi. Estimativa do Balanço de Radiação por Sensoriamento Remoto de diferentes usos de Solo no Sudoeste da Amazônia Brasileira. Sociedade \& Natureza (ufu. Online), v. 27, p. 341-356, 2015. https://doi.org/10.1590/1982-451320150211

SILVA, B. B. da; LOPES, Gláucia Miranda; AZEVEDO, Pedro Vieira de. Balanço de radiação em áreas irrigadas utilizando imagens Landsat 5 - TM. Revista Brasileira de Meteorologia, São Paulo - SP, v. 20, n.2, p. 243-252, 2005.

TUBELIS, A. E NASCIMENTO, F.J.L. do. Meteorologia Descritiva: fundamentos e aplicações brasileiras / Antônio Tubelis, Fernando José Lino do Nascimento. - São Paulo: Nobel, 1980. p. - 374.

UDA, P. K.; CORSEUIL, C. W.; KOBIYAMA, M. Mapeamento do Saldo de Radiação da Bacia do Alto Rio Negro, Região Sul Brasileira. Revista Brasileira de Recursos Hídricos, v. 18, p. 249-258, 2013. https://doi.org/10.21168/rbrh.v18n2.p249-258

URQUIAGA, S.; ALVES, B.J.R.; JANTALIA, C.P.; BODDEY, R.M. Variações no Estoque de Carbono e Emissões de Gases de Efeito Estufa em Solos das Regiões Tropicais e Subtropicais do Brasil: uma análise crítica. Piracicaba - SP: International Plant Nutrition Institute, 2010.

VAREJÃO-SILVA, M.A. Meteorologia e Climatologia. 1 E, Brasília, DF. Instituto Nacional de Meteorologia - INMET, 2000. 532p.

VAREJÃO-SILVA, M.A. Meteorologia e Climatologia. Versão digital 2 - Recife, 2006.

VON RANDOW, C.; MANZI, A.O.; KRUIJT, B.; OLIVEIRA, P.J.; ZANCHI, F.B.; SILVA, R.L.; HODNETT, M.G.; GASH, J.H.C.; ELBERS, J.A.; WATERLOO, M.J.; CARDOSO, F.L.; KABAT, P. Comparative measuremen Temperatura de superfície and seasonal variations in energy and carbon Exchange over Forest and pasture in South West Amazonia. Theoretical and Applied Climatology, v.78, p. 5-26, 2004. https://doi.org/10.1007/s00704-004-0041-z

QUERINO, C. A. S.; MOURA, M. A. L.; LYRA, R. F. F.; MARIANO, G. L. Avaliação e comparação de radiação solar global e albedo com Ângulo zênital na região Amazônica. Revista Brasileira de Meteorologia, v. 21, n. Especial, p. 42-49, 2006.

Recebido em: 16/03/2019

Aceito para publicação em: 12/08/2019 